\title{
THE EFFECT OF TRIMETAZIDINE ON C-REACTIVE PROTEIN, CYTOKINES AND ADHESION MOLECULES IN THE COURSE OF ACUTE MYOCARDIAL INFARCTION
}

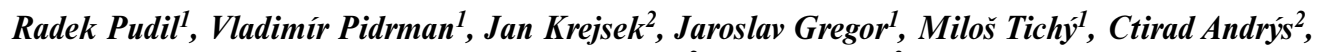 \\ Marcela Drahošová2, Václav Bláha ${ }^{3}$
}

\begin{abstract}
Charles University in Prague, Faculty of Medicine in Hradec Králové: $2^{\text {nd }}$ Department of Medicine ${ }^{1}$; University Teaching Hospital in Hradec Králové: Department of Clinical Immunology and Allergology²; Purkyně Military Medical Academy in Hradec Králové Department ${ }^{3}$
\end{abstract}

\begin{abstract}
Summary: The aim of this randomised, double-blind, placebo controlled, parallel group study was to assess the effect of trimetazidine (TMZ), a potent antiischaemic drug, on plasma C-reactive protein (C-RP), cytokine and adhesion molecule levels. The study population consists of 18 patients (16 males, 2 females, average age $56.45 \pm 10.97$ years) with acute myocardial infarction admitted within 6 hours after onset of symptoms and treated with streptokinase. Blood samples were taken at 3-hour intervals during the time of treatment. All patients were randomised blindly using a centralised randomisation process, between trimetazidine ( $40 \mathrm{mg}$ bolus iv. then $60 \mathrm{mg}$ per day for 48 hours intravenously in glucose infusion) or placebo group. Plasma C-RP level was significantly lower in TMZ group $(39.5 \mathrm{mg} / \mathrm{ml} \pm 9.7 \mathrm{mg} / \mathrm{ml})$ as compared to placebo $(75.7 \pm 29.4 \mathrm{mg} / \mathrm{ml}, \mathrm{p} \leq 0.001)$ and peaked 28 hours later in TMZ group. Plasma interleukin 6 (IL 6) level showed a sharp peak 9 hours after the onset of the symptoms in TMZ group $(116.9 \pm 180.2 \mathrm{pg} / \mathrm{ml} \mathrm{vs} .45 .4 \pm 37.9 \mathrm{pg} / \mathrm{ml})$ and was increased up to 30 hours after the onset of the symptoms. Plasma interleukin 1 beta (IL $1 \beta$ ) was also higher in TMZ group notably 21 hours after the onset of symptoms $(26.4 \pm 9.3 \mathrm{pg} / \mathrm{ml} \mathrm{vs} .16 .2 \pm 2.4 \mathrm{pg} / \mathrm{ml})$. TMZ group showed lower plasma E-selectin levels. Plasma IL 8, TNF $\alpha$ and ICAM 1 levels were without statistical significant differences. The present study demonstrates a significant reduction of plasma C-reactive protein level in the course of acute myocardial infarction treated with streptokinase and intravenous trimetazidine infusion compared with the group of patients without trimetazidine treatment.
\end{abstract}

Key words: Trimetazidine; Acute myocardial infarction; C-reactive protein; Interleukins; Adhesion molecules

\section{Introduction}

The association of inflammation with acute myocardial infarction (AMI) has been known for over a half of the century. Inflammatory lesions seen in tissue specimens many hours to days after the onset of infarction reflect, in part, a healing process. In recent years many investigators have studied the potential pathogenic role of inflammation in the myocardial ischaemia-reperfusion $(\mathrm{MI} / \mathrm{R})$ process (11).

Inappropriate inflammatory response can cause severe tissue destruction. During ischaemia-reperfusion, such as in acute myocardial infarction, the tissue damage may result not only from direct anoxic and hypoxic injury but also from other deleterious events occurring after the blood flow reestablishment to the occluded vascular bed. Reperfusion injury is partly caused by oxygen radicals, proteolytic enzymes and cytokines released by adhered and activated leucocytes that infiltrate into the affected area, because neutrophil depletion or prevention of neutrophil accumulation significantly diminishes tissue damage and enhances the recovery of cardiac function (5).

Recent studies have focused on the possible role of the soluble early mediators of acute phase response during MI/R process. Particular emphasis has been given to the study of acute response proteins (C-reactive protein, $\alpha_{1}$ antitrypsin, serum amyloid) and cytokines.

Key role of interleukin 1beta (IL $1 \beta$ ), interleukin 6 (IL 6), interleukin 8 (IL 8), and tumor necrosis factor alpha (TNF $\alpha$ ) in the process of lymphocyte, neutrophil, and platelet activation has been shown in previous studies $(8,9,12,14)$. Elevation of plasma IL1 $\beta$, IL 6 , IL 8 , TNF $\alpha$, and soluble adhesion molecule levels (ICAM 1, E-selectin etc.) in the course of ischaemic event have been studied extensively. Based on these observations, new medications should have protective effect on myocytes, preserve myocardial cell function by decreasing ischaemic and reperfusion effect, and limit the area of necrosis. 
Trimetazidine [TMZ, (1-(2,3,4-trimetoxybenzyl)] piperazine dichloride has cytoprotective properties and prevents metabolic disturbances that result from myocardial ischaemia. Its mechanism of action is, at least partially, directly related to the mitochondrial enzymatic systems. TMZ stimulates glucose oxidation by primarily reducing rates of $\beta$-oxidation (6), decreasing mitochondrial oxygen demand. TMZ has also been reported to have a protective effect in myocardial ischaemia-reperfusion process by increasing phospholipids turnover of the membrane (13). After periods of ischaemia it is able to improve cardiac function and reduce both the decrease in intracellular $\mathrm{pH}$ and ATP content $(3,7)$. TMZ has been reported to reduce the neutrophil accumulation in myocardium during the ischaemia-reperfusion process (15).

The objective of our study was to assess the effect of $\mathrm{TMZ}$ on inflammatory response to acute myocardial infarction and to elucidate if $\mathrm{TMZ}$ can reduce interleukin and adhesion molecule production. Therefore, plasma C-reactive protein, IL $1 \beta$, IL 6, IL 8 , TNF $\alpha$, and soluble adhesion molecule levels were measured in the course of 96 hours AMI.

\section{Material and methods}

\section{Study population}

The study subjects consisted of eighteen patients with AMI (16 men and 2 women; mean age 56.45 years, ranging from 39 to 71 years) who were admitted within $6 \mathrm{~h}$ after the onset of the symptoms. They were treated by thrombolytic (streptokinase) therapy and randomised blindly, through a centralized randomisation process, to a trimetazidine or placebo group. The TMZ group consisted of 5 men and 1 woman (mean age 55.06 years \pm 11.11 years) the placebo group had 11 patients (10 men, 1 woman, mean age 57.18

Tab. 1: Characteristics of study group.

\begin{tabular}{|c|c|c|c|}
\hline Variable & TMZ (n 7) & Placebo (n 11 & $\mathrm{p}$ \\
\hline Age (years) $($ mean \pm SD) & $55(11.10)$ & $57,18(11.78)$ & $\mathrm{ns}$ \\
\hline Female gender $(\%)$ & 14.3 & 9.1 & ns \\
\hline Diabetes mellitus (\%) & 42.8 & 36.4 & ns \\
\hline Arterial hypertension (\%) & 57.4 & 54.5 & $\mathrm{~ns}$ \\
\hline History of MI (\%) & 28.6 & 27.3 & ns \\
\hline Dyslipidemia (\%) & 42.8 & 27.3 & $\mathrm{~ns}$ \\
\hline Smoking (\%) & 57.2 & 36.4 & ns \\
\hline AMI location - anterior (\%) & 42.8 & 45.5 & ns \\
\hline - inferior $(\%)$ & 28.6 & 18.2 & ns \\
\hline Peak CK level ( $\mu$ kat/L) & $26.1 \pm 15.1$ & $31.5 \pm 28.5$ & $\mathrm{~ns}$ \\
\hline \multicolumn{4}{|l|}{$($ mean $\pm \mathrm{SD})$} \\
\hline Killip class $>2(\%)$ & 14.3 & 9.1 & $\mathrm{~ns}$ \\
\hline $\mathrm{BP}$ on admission $(\mathrm{mmHg})$ & $137 / 86$ & $132 / 75$ & $\mathrm{~ns}$ \\
\hline HR on admission (BPM) & 84.6 & 88.8 & ns \\
\hline
\end{tabular}

AMI - acute myocardial infarction, BP - systemic blood pressure, HR - heart rate, SD - standard deviation. years \pm 11.57 years). There were no significant differences between the two groups. Table No.1 shows the characteristics of the study population. In the second week some of them underwent coronary arteriography.

\section{Inclusion criteria}

The diagnosis of suspected myocardial infarction was based on the following two criteria:

- A typical thoracic pain occurring within the previous 6 hours: prolonged (more than 30 minutes) or for less than 30 minutes, but still present and resistant to sublingual nitrates

And:

- typical ECG tracing with $2 \mathrm{~mm}$ or greater ST segment elevation in at least two leads or atypical but with highly probable previous history of coronary disease.

All patients had a confirmed diagnosis of AMI by biochemical changes (elevation of the serum creatine kinase and $\mathrm{MB}$ iso-enzyme level more than twice the normal upper limit).

Exclusion criteria were serious renal or liver failure, pregnancy, patients having taken TMZ within the last 48 hours, patients treated with established or experimental antioxidants, patients treated with fibrinolytic therapy within the last 24 hours, successful resuscitation, serious systemic connective tissue diseases, acute and inflammatory disorders, refusal of the informed consent.

The average time from onset of the symptoms to admission was 146,76 min.

The study protocol was approved by the Ethic Committee of our institution.

\section{Treatment of the patients}

The TMZ treatment comprised:

TMZ group - intravenous bolus of $40 \mathrm{mg}$ of TMZ followed by a continuous TMZ infusion $60 \mathrm{mg} / 24$ hours for 48 hours. The bolus of a $40 \mathrm{mg}$ TMZ was injected intravenously over 2 minutes before thrombolysis. For the continuous infusion, $6 \mathrm{ml}$ ( $60 \mathrm{mg}$ of TMZ), was diluted in a $5 \%$ glucose solution, $500 \mathrm{ml}$ and was administered over 24 hours. A control group received intravenously a placebo with the same regimen.

\section{Blood samples}

The first blood sample was taken immediately after admission and then at $3 \mathrm{~h}$ intervals during the first 48 hours, at $6 \mathrm{~h}$ intervals during the next $48 \mathrm{~h}$. The blood was immediately centrifuged; aliquot parts of plasma were stored at $20^{\circ} \mathrm{C}$ overnight and stored at $-70^{\circ} \mathrm{C}$ until the assessment of the immune parameters the plasma samples. Plasma levels of circulating IL $1 \beta$, IL 6, IL 8, ICAM 1 and E-selectin were measured using commercial enzyme-linked immunosorbant assay (ELISA) developed by RD Quantikinine, Minneapolis, MN, USA. TNF $\alpha$ was measured by using the commercial ELISA set purchased from Immunotech, Marseille, France. 


\section{Biochemical measurements}

Serum creatine kinase was measured by Hitachi 704 autoanalyser using diagnostic kits of activated CK-NAC by the enzymatic assessment method developed by Boehringer, Mannheim, Germany. The plasma C-RP levels were measured by single radial immunodiffusion using antiserum USOL Prague, Czech Republic and the Behring standard.

\section{Statistical analysis}

Data were expressed as mean and standard deviation (SD). Analysis of the differences between patients treated with TMZ and placebo was made by using the analysis of variance (ANOVA) design. The differences were considered to be significant at $\mathrm{p}$ values less than $0.05(\mathrm{p}<0.05)$

\section{Results}

7 patients received TMZ (intravenous bolus of 40mg in 2 minutes, then $60 \mathrm{mg}$ TMZ daily in glucose solution for 48 hours), and 11 were treated with placebo. In-hospital management is shown in table No.2.

Tab. 2: In-hospital management.

\begin{tabular}{|l|c|c|c|}
\hline Variable & TMZ (n 7) & Placebo (n 11) & $\mathrm{p}$ \\
\hline Coronary angiography (\%) & 57.2 & 45.5 & $\mathrm{~ns}$ \\
\hline PTCA in hospital (\%) & 28.6 & 27.3 & $\mathrm{~ns}$ \\
\hline Beta blockers (\%) & 100 & 91 & $\mathrm{~ns}$ \\
\hline ACE inhibitors (\%) & 57.2 & 55.5 & $\mathrm{~ns}$ \\
\hline Acetylsalicylic acid (\%) & 100 & 100 & $\mathrm{~ns}$ \\
\hline Nitrates (\%) & 100 & 100 & $\mathrm{~ns}$ \\
\hline Diuretics (\%) & 42.9 & 45.5 & $\mathrm{~ns}$ \\
\hline Ca blockers (\%) & 28.6 & 27.3 & $\mathrm{~ns}$ \\
\hline
\end{tabular}

\section{Plasma C-RP level (fig. 1)}

The plasma C-RP level was elevated in both groups. Statistically significant differences were found in the interval from 18 to 60 hours after the onset of the symptoms. TMZ group showed a $52 \%$ significantly less elevation of the plasma C-RP level than the placebo group, $(75.7 \mathrm{mg} / \mathrm{ml} \pm$ $29.4 \mathrm{mg} / \mathrm{ml}$ vs. $39.5 \mathrm{mg} / \mathrm{ml} \pm 9.7 \mathrm{mg} / \mathrm{ml}, \mathrm{p}<0.001)$. The peak plasma C-RP level $(76.8 \mathrm{mg} / \mathrm{ml} \pm 34.1 \mathrm{mg} / \mathrm{ml})$ of the placebo group occurred 54 hours after onset of the symptoms as compared peak plasma C-RP level of the TMZ group $(52.6 \mathrm{mg} / \mathrm{ml} \pm 23.1 \mathrm{mg} / \mathrm{ml})$ which was measured 78 hours after the onset of the symptoms (i.e. 28 hours after the peak of the placebo group).

\section{Plasma TNF $\alpha$ (fig. 2)}

The plasma TNF $\alpha$ levels of both groups were elevated throughout the time of the observation, but neither group has shown significant differences. The peak plasma TNF $\alpha$ level of the TMZ group $(40.6 \mathrm{pg} / \mathrm{ml} \pm 28.7 \mathrm{pg} / \mathrm{ml})$ was achieved 60 hours after the onset of the symptoms as compared to, the peak of the placebo group $(71.1 \mathrm{pg} / \mathrm{ml} \pm 60.1 \mathrm{pg} / \mathrm{ml})$, which was achieved 90 hours after the onset of the chest pain.

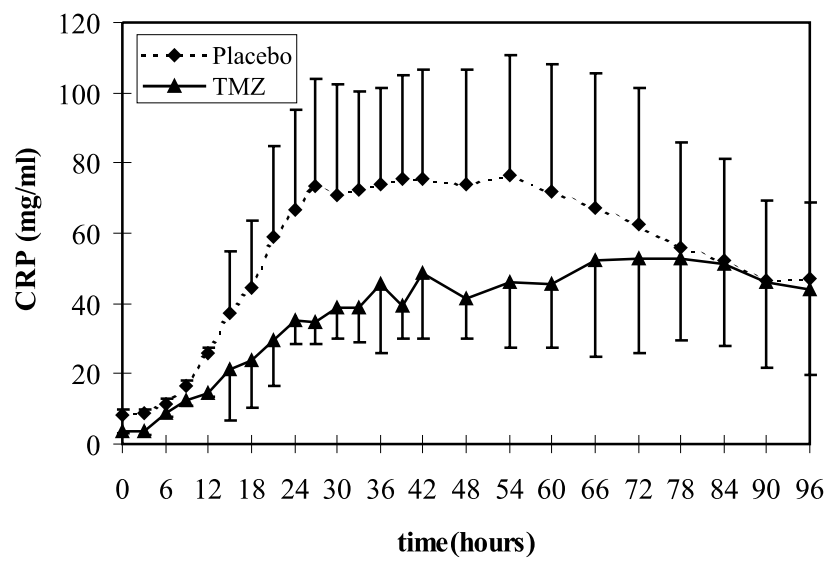

Fig. 1: Mean plasma CRP levels $(\mathrm{mg} / \mathrm{ml})$ and SD in TMZ $(-\mathbf{\Delta}-)$ and placebo (- - -) groups in the course of 96 hours AMI.

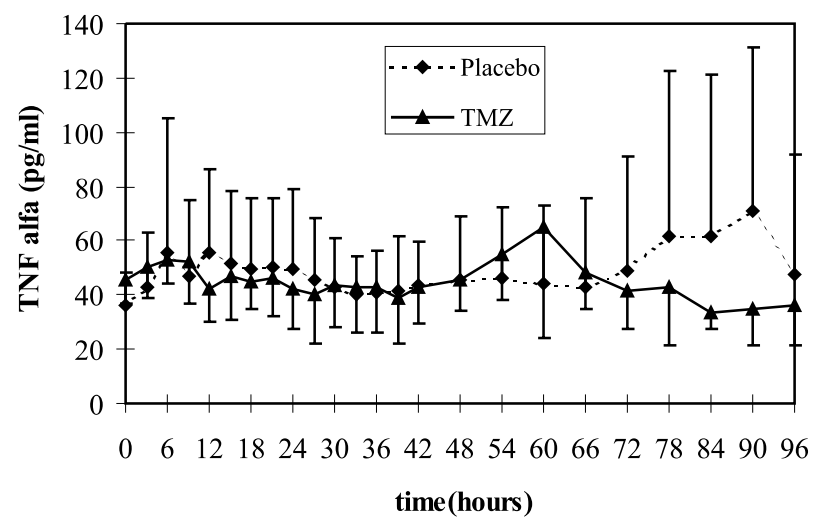

Fig. 2: Mean plasma TNF alpha levels $(\mathrm{pg} / \mathrm{ml})$ and SD in TMZ ( $-\boldsymbol{\Delta}-)$ and placebo (- - -) groups in the course of 96 hours AMI.

\section{Plasma IL $1 \beta$ (fig. 3)}

The plasma IL $1 \beta$ levels were also elevated in both groups. Plasma IL $1 \beta$ levels of the TMZ group were higher almost all of the time during the observation course (except at 96 hour after the onset of the symptoms, when plasma IL $1 \beta$ level of placebo group was only slightly elevated). Plasma level elevation of the TMZ group was statistically significant 21 hours after the onset of the symptoms $(26.4 \mathrm{pg} / \mathrm{ml} \pm 9.3 \mathrm{pg} / \mathrm{ml}$ vs. $16.2 \mathrm{pg} / \mathrm{ml} \pm 2.4$ $\mathrm{pg} / \mathrm{ml} \mathrm{p}<0.001)$.

\section{Plasma IL 6 (fig. 4)}

Plasma IL 6 levels of the TMZ group showed a sharp peak 9 hours after the onset of the symptoms $(116.9 \mathrm{pg} / \mathrm{ml}$ $\pm 180.2 \mathrm{pg} / \mathrm{ml}$ vs. $45.4 \mathrm{pg} / \mathrm{ml} \pm 37.9 \mathrm{pg} / \mathrm{ml}, \mathrm{p}=\mathrm{n} . \mathrm{s}$. $)$. The plasma IL 6 level was increased from the beginning of the observation to 30 hours after the onset of the symptoms. 


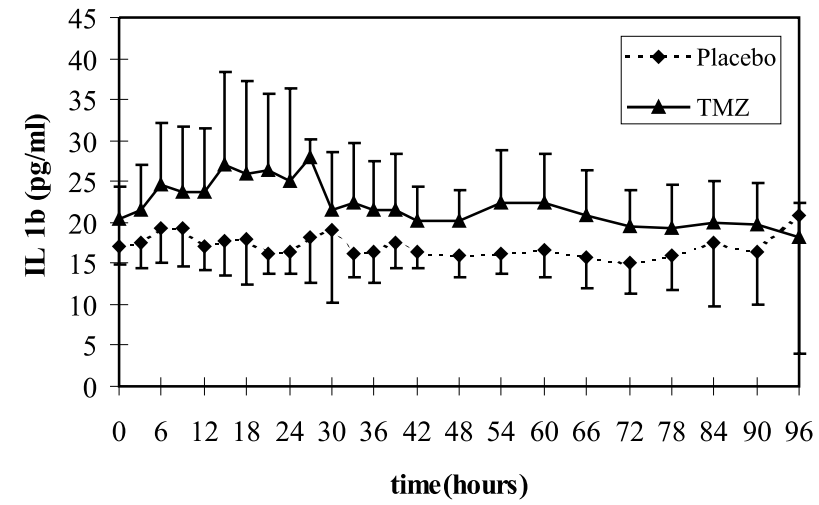

Fig. 3: Mean plasma IL 1beta levels $(\mathrm{pg} / \mathrm{ml})$ and SD in TMZ (- $\mathbf{\Delta}-)$ and placebo (- - -) groups in the course of 96 hours AMI.

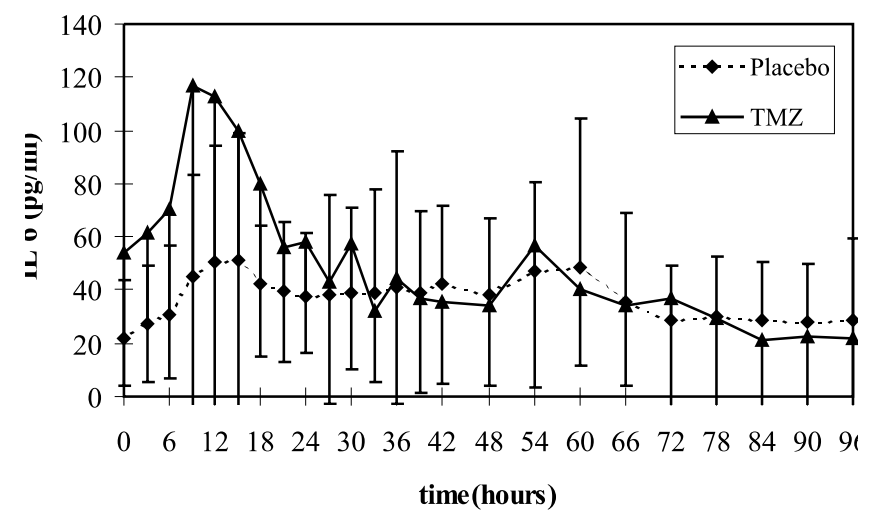

Fig. 4: Mean plasma IL 6 levels $(\mathrm{pg} / \mathrm{ml})$ and SD in TMZ $(-\boldsymbol{\Delta}-)$ and placebo (- - -) groups in the course of 96 hours AMI.

\section{Plasma IL 8 (fig. 5)}

Plasma IL 8 levels were elevated in both groups, but without any significant differences between them. While the peak plasma IL 8 level of the TMZ group was achieved 96 hours after admission $(136.8 \mathrm{pg} / \mathrm{ml} \pm 88.4 \mathrm{pg} / \mathrm{ml})$, the peak plasma in the placebo group was achieved 72 hours after admission $(136.5 \mathrm{pg} / \mathrm{ml} \pm 75.2 \mathrm{pg} / \mathrm{ml})$.

\section{Plasma adhesion molecule levels (figs. 6 and 7)}

TMZ group showed a more rapid achievement of the peak plasma E-selectin level 6 hours after admission (117.8 $\mathrm{ng} / \mathrm{ml} \pm 35.9 \mathrm{ng} / \mathrm{ml}$ ). Plasma level then decreased slightly until the end of the observation time course. Between 9 to 96 hours after onset of the symptoms E-selectin levels were much lower than in the placebo group, which achieved the peak level of $174.6 \mathrm{ng} / \mathrm{ml} \pm 160.0 \mathrm{ng} / \mathrm{ml} 36$ hours after the admission.

Plasma levels of ICAM 1 were non significantly different between the two groups. Plasma ICAM 1 level of the TMZ group was elevated for the first 24 hours. In the next two days, plasma ICAM 1 level was elevated in the placebo group.

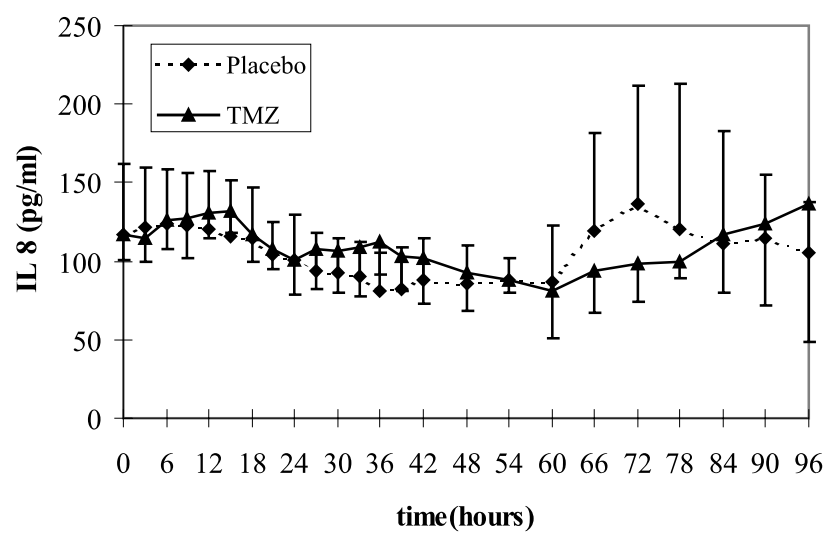

Fig. 5: Mean plasma IL 8 levels $(\mathrm{pg} / \mathrm{ml})$ and SD in TMZ $(-\mathbf{\Delta}-)$ and placebo (- - ) groups in the course of 96 hours AMI.

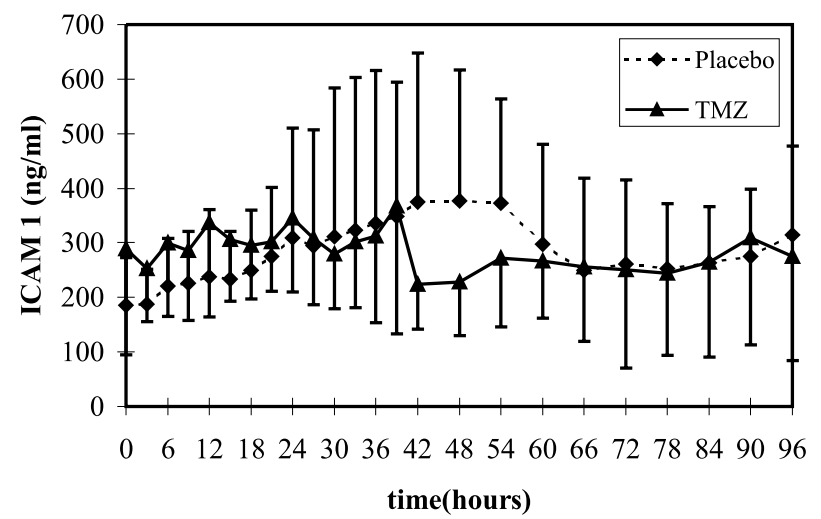

Fig. 6: Mean plasma E selectin levels $(\mathrm{ng} / \mathrm{ml})$ and SD in TMZ ( $-\boldsymbol{\Delta}-)$ and placebo (- - - $)$ groups in the course of 96 hours AMI.

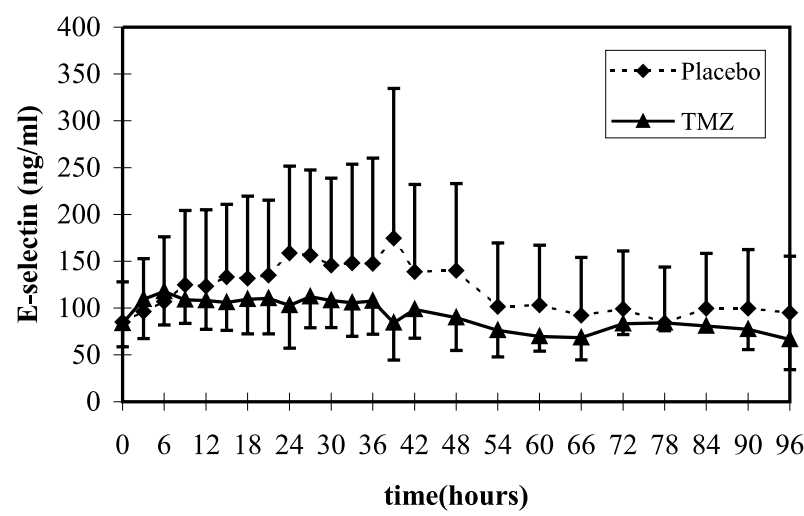

Fig. 7: Mean plasma ICAM 1 levels $(\mathrm{ng} / \mathrm{ml})$ and SD in TMZ (- $\mathbf{A}-)$ and placebo (- - - ) groups in the course of 96 hours AMI.

Plasma CK levels (fig. 8)

Fig. No.8 shows the plasma CK levels in both groups of patients. Mean plasma CK levels of the placebo group were slightly more elevated compared to the TMZ group. Peak 
plasma CK levels in both groups was achieved 9 hours after the onset of symptoms and reached $31.5 \pm 28.5 \mu \mathrm{kat} / \mathrm{ml}$ in placebo group vs. $26.1 \mu \mathrm{kat} / \mathrm{ml} \pm 15.1 \mu \mathrm{kat} / \mathrm{ml}$ in $\mathrm{TMZ}$ group, $\mathrm{p}$ non significant. There were no significant differences between the two groups.

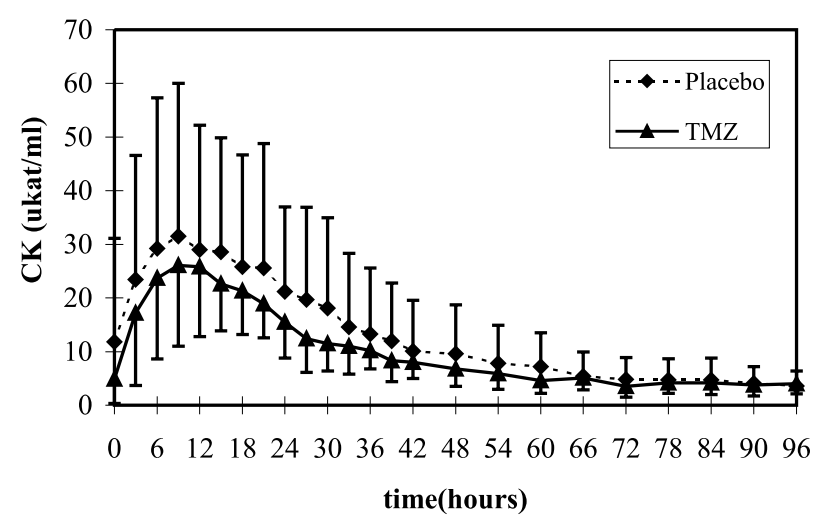

Fig. 8: Mean plasma CK levels ((kat/l) and SD in TMZ $(-\boldsymbol{\Delta}-)$ and placebo (- - $)$ groups in the course of 96 hours AMI.

\section{Discussion}

Previous studies evidenced the cytoprotective effect of trimetazidine during ischaemia and reperfusion. In a placebo-controlled study, Fabiani et al. (4) showed myocardial metabolism and left ventricular function improved compared to placebo in patients receiving trimetazidine before and during cardiac surgery. Animal studies have shown that trimetazidine protects the myocardium from ischaemia and reperfusion during experimental myocardial infarction. Belcher et al. (1) showed that TMZ limits myocardial necrosis in rabbits, which received TMZ before a coronary artery ligation. Promising data from experimental studies have been encouraging regarding trimetazidine administration in acute ischaemia induced by coronary ligation in rabbits (15).

Recent studies have shown that trimetazidine is directly improving a metabolic status of the myocardium by inhibition of fatty acid oxidation (6), and reduction of the ionic imbalance induced by ischaemia. This metabolic modulation has been proved to indirectly reduce the ionic imbalance and improve myocardial function $(3,7)$.

We examined the effect of trimetazidine on the cytokines, adhesion molecule levels and plasma C-RP levels in the course of AMI treated by streptokinase. We found a significant elevation of C-reactive protein in the placebo group as compared with the TMZ treated group. This observation supports the hypothesis that TMZ could reduce the inflammatory response to ischaemia also by improving a glucose metabolism in the ischemic area. This process can reduce an inflammatory response, and intercellular interactions. This observation is compatible with the experiment of Williams (15), showing that TMZ inhibits the neutrophil accumulation in the infarcted area.

Extravascular neutrophil migration depends on generation or release of chemoattractants agents and on initial adhesion of leukocytes to vascular endothelium. The latter process is mediated by adhesion molecules expressed on the surface of both neutrophil and endothelial cells. To determine whether trimetazidine affects release of plasma chemoattractant substances and the expression of adhesion molecules, plasma interleukin (IL $1 \beta$, IL 8, TNF $\alpha$, IL 6) and adhesion molecules (E-selectin and ICAM 1) levels were examined. Although plasma levels of these cytokines have been elevated throughout the observation period, there was no significant difference in plasma levels of these interleukins and adhesion molecules of patients treated with TMZ compared with subjects on placebo.

In spite of the fact that plasma $\mathrm{CK}$ level can reflect the size of myocardial necrosis, we did not find a statistical difference in plasma CK level between the placebo and TMZ group. We also didn't find strong positive correlation between the plasma C-RP and CK levels.

Furthermore, it is known, that neutrophil accumulation in the ischaemic area is dependent on expression of CD $11 /$ CD18 adhesion molecules levels (10) and interleukin 1 beta elicits neutrophil accumulation not through a direct action on the leukocytes, but more often by increased expression of endothelial adhesion molecule 1 (E selectin) and intercellular adhesion molecule 1 (ICAM 1). At this time we have no sufficient explanation for the inhibition of neutrophil accumulation in the infarct site.

Despite the limitations (small number of the patients, and inability to compare the size of the infarcted area), our study has shown the significant effect of trimetazidine on plasma C-RP level, which was lower as compared with the placebo group. The study has also shown that TMZ suppressed neutrophil accumulation is not dependent on plasma chemoattractants such as interleukin 1 beta, interleukin 8 and adhesion molecules.

\section{Acknowledgements}

The study was supported by a grant from The Ministry of Health of the Czech Republic, No. 1944-2, and realised with the support of Laboratories Servier.

\section{References}

1. Belcher PR, Drake-Holland AJ, Noble M. Trimetazidine w zawale serca. Wyniki badan eksperymentalnych. Kardiol Pol 1996;45(suppl IV):15-20.

2. Drake-Holland AJ, Belcher PR, Hynd J, Noble NIM. Infarct size in rabbits: a modified method illustrated by effects of propranolol. Bas Res Cardiol 1993;88:250-8.

3. El Banani $\mathrm{H}$, Bernard $\mathrm{M}$, Baetz $\mathrm{D}$ et al. Changes in intracellular sodium and $\mathrm{pH}$ during ischaemia-reperfusion are attenuated by trimetazidine. Comparison between low- and zero-flow ischaemia. Cardiovasc Res 2000;47:688-96.

4. Fabiani NJ, Ponzio O, Emerit I et al. Crdioprotective effect of trimetazidine during coronary artery graft surgery. J Cardiovasc Surg 1992;33:486-91.

5. Jaakkola K, Jalkanen S, Kaunismaki $\mathrm{K}$ et al.Vascular Adhesion Protein-1, Intercellular Adhesion Molecule-1 and P-Selectin Mediate Leukocyte Binding to Ischemic Heart in Humans. J Am Coll Cardiol 2000; 36:122-9.

6. Kantor PF, Lucien A, Kozak R, Lopaschuk G D. The Antianginal Drug Trimetazidine Shifts Cardiac Energy Metabolism From Fatty Acid Oxidation to 
Glucose Oxidation by Inhibiting Mitochondrial Long-Chain 3-Ketoacyl Coenzyme A Thiolase. Circ Res 2000;86:580-8.

7. Lagadic-Gossmann D, Le Pringent K, Feuvray D. Effects of trimetazidine on $\mathrm{pH}$ regulation in the rat isolated ventricular myocyte. Br J Pharmacol 1996;117:831

8. Maury CPJ, Teppo AM. Circulating tumor necrosis factor- $\alpha$ (cachectin) in myocardial infarction. J Int Med 1989;25:333-6.

9. Neumann FJ, Ott I, Gavaz H et al. Cardiac release of cytokines and inflammatory response in acute myocardial infarction. Circulation 1995;92:748-55.

10. Nourshang S, Rampart M, Hellwell PG et al. Accumulation of ( ${ }^{111}$ In) neutrophils in rabbit skin in allergic and non-allergic inflammatory reactions in vivo: inhibition by neutrophil pre-treatment in vitro with a monoclonal antibody recognising the CD18 antigen. J Immunol 1989;142:3193-8.

11. Pannitteri G, Marino B, Campa P, Martucci R, Testa U, Peschle C. Interleukin 6 and 8 as mediators of acute phase response in acute myocardial infarction. Am J Cardiol 1997;80:622-5.

12. Pudil R, Pidrman V, Krejsek $\mathbf{J}$ et al. Cytokines and adhesion molecules in the course of acute myocardial infarction. Clinica Chimica Acta 1999;280:127-34.

13. Sentex E, Sergiel JP, Lucien A and Grynberg A. Trimetazidine increased phospholipid turnover in ventricular myocytes. Mol Cell Biochem 1997;175: $153-62$.
14. Sturk A, Hack CE, Aarder LA, Brouwer M, Koster RRW, Sanders GTB. Interleukin 6 release and acute-phase reaction in patients with acute myocardial infarction: a pilot study. J Lab Clin Med 1992;119:574-9.

15. Williams FM, Tanda K, Kus M, Williams TJ. Trimetazidine inhibits neutrophil accumulation after myocardial ischaemia and reperfusion in rabbits. J Cardiovasc Pharmacol 1993,22:828-33.

Submitted June 2001.

Accepted November 2001.

MUDr. Radek Pudil, Ph.D., Charles University in Prague, Faculty of Medicine in Hradec Králové, $2^{\text {nd }}$ Department of Medicine, Pospísilova 360, 50005 Hradec Králové,

Czech Republic. e-mail: pudil@fnhk.cz 